\title{
Imagen estática frente a animación en la comprensión escrita y la adquisición de vocabulario
}

\author{
Joaquín Martín Iglesias
}

Profesor de Enseñanza Secundaria, IES Alonso de Orozco, Oropesa (Toledo)

\section{España}

ejoacko@gmail.com 


\section{Resumen}

Introducción. Este artículo pretende revisar algunas de las experiencias llevadas a cabo que integran, en menor o mayor grado, el uso de elementos multimedia para la enseñanza/aprendizaje de una lengua no nativa. Gracias a esta base, vamos a analizar las características, diferencias y los efectos que pueden tener la imagen estática y la animación sobre dichos procesos, para concluir con una experiencia realizada con alumnos españoles de $4^{\circ}$ de la ESO y que formó parte de la Tesis Doctoral de J.P. Martín (2006): Aprendizaje de vocabulario y ELAO: análisis experimental y comparativo entre actividades tradicionales y con recursos multimedia, en la enseñanza del inglés como lengua extranjera”

Método. Diseño de actividades impresas y multimedia para una experiencia con alumnos de $4^{\mathrm{o}} \mathrm{ESO}$, tests de seguimiento y entrevistas para la obtención de datos sobre adquisición y retención de vocabulario en inglés como lengua extranjera.

Resultados. El uso coherente y controlado de la animación en actividades mutimedia es muy superior al uso de la imagen estática, en igualdad de condiciones.

Discusión y Conclusión. Aunque los resultados obtenidos en esta investigación demuestran la validez de los estudios teóricos y prácticos previos, y su adaptación a alumnos españoles de ESO con L1 castellano, es necesario un número mayor de los mismos para ofrecer unos datos de carácter universal. Esa es la principal razón por la que se está desarrollando un proyecto de colaboración e investigación entre la UNED y el IES Alonso de Orozco (Oropesa-Toledo), durante dos años académicos. Su principal objetivo es llegar a conclusiones más importantes sobre el uso de diferentes medios y su efecto sobre la adquisición y retención léxica, la motivación, la comprensión lectora y la integración de alumnos con necesidades educativas especiales.

Palabras Clave: vocabulario, ELAO, multimedia, TIC, imagen estática, animación, comprensión escrita.

Recepción del artículo: 10-03-2007

Aceptación provisional: $\quad$ 29-04-2007

Aceptación definitiva: $\quad$ 18-05-2007 


\section{Introducción}

Aunque se habla del uso de las Nuevas Tecnologías Aplicadas a la Educación como algo muy novedoso y, además, son muchos los estudios que se han realizado recientemente sobre este tema, es cierto que queda mucho aún por analizar y desarrollar. Garrett (1989) denominó esta nueva aproximación a la adquisición de una segunda lengua como new humanism. Este nuevo humanismo es un fenómeno que, utilizando medios informáticos para la enseñanza, aglutina a investigadores y especialistas de áreas muy distintas. Esta tecnología favorece la revisión de las bases científicas ya tradicionales y las actualiza para, finalmente, reformularlas proponiendo una nueva aproximación. Ésta es la línea de acción actual y que promete aportar mucho en el futuro, como ya lo está apuntando en el presente.

Esta idea que acabamos de mencionar, apoyada por numerosos investigadores como Pennington (1996), Levy (1997), o Warschauer y Healey (1998), dio lugar a la que conoce con el nombre de ELAO. Entre las muchas facetas positivas que ELAO puede ofrecer a la enseñanza/aprendizaje de una segunda lengua, se ha destacado siempre su carácter multimedia, es decir, la presentación de un input utilizando simultáneamente diferentes medios: texto, audio, imagen, vídeo, etc. Por esta razón, son muchos los investigadores como Hofstetter (1994) que consideran a ELAO y, en especial, su actualización ELAOI que combina multimedia e interactividad, como una verdadera revolución en el campo de la enseñanza/aprendizaje de lenguas extranjeras.

Como ya apuntábamos anteriormente, este nuevo humanismo no pretende desplazar las investigaciones anteriores, sino retomarlas y actualizarlas para acomodar estas nuevas herramientas lingüísticas que se derivan de las llamadas TIC (Tecnologías de la Información y la Comunicación). En especial y dada su relación con el tema principal de este estudio, debemos destacar dos planteamientos teóricos de vital importancia, directamente relacionados con la visión chomskiana del conocimiento de una lengua (Chomsky, 1986): la Hipótesis sobre el Input de Krashen (1985) y la Teoría de la Codificación Dual de Paivio (1986). El primero parte de la idea que humans acquire language in only one way -by understanding messages or by receiving "comprehensible input" ("los seres humanos adquieren la lengua de una única forma, con la comprensión de mensajes o por la recepción de un "input comprensible", p.2). Por tanto, si el individuo lee o escucha una frase con significado y consigue comprenderla, entonces se está produciendo la adquisición de L1 o L2. Sin embargo, si dicha frase no tiene 
significado para el individuo, puede incluso conocer la forma pero no el significado, se produce un bloqueo mental que dificulta la adquisición.

Para Krashen y Terrell (1983), adults have two distinctive ways of developing competences in second languages ... acquisition, that is, by using language for real communication ... learning ... "knowing about the language ("los adultos poseen dos vías distintas para el desarrollo de competencias en una segunda lengua ... la adquisición, es decir, gracias al uso de la lengua para la comunicación real.. el aprendizaje "conocer la lengua", p. 26). A juzgar por estas palabras, la adquisición de una segunda lengua se produciría de forma muy similar a la materna en muchos aspectos. En primer lugar, tendremos una adquisición de conocimientos que están en relación directa con el uso de una segunda lengua, pero que se producen de forma inconsciente, sin memorización de ningún tipo, como simple asimilación. En segundo lugar, en dicho proceso de adquisición de una lengua distinta de la materna se suele producir el aprendizaje consciente de elementos, reglas, vocabulario, etc. Aunque ambos procesos, adquisición y aprendizaje, son importantes en la adquisición de una segunda lengua, hay que destacar que con el último no se suele expresar algo en ella, se conoce cómo es y cómo funciona dicha lengua, pero para poner todo ese conocimiento en práctica es necesaria la adquisición. Para lograr utilizar la lengua materna, la adquisición es vital e imprescindible mientras que el aprendizaje no siempre se da. Por ejemplo, podemos memorizar (aprendizaje) todas las preposiciones, pero eso no quiere decir que sepamos utilizarlas (adquisición-asimilación retención).

El formato ELAO y el uso de medios gráficos se basa precisamente en fomentar dicha adquisición, gracias a la creación de imágenes mentales que son fácilmente transformables en conocimiento. En cierta manera, el entorno virtual y la interactividad diseñados de forma coherente, reproducen el contexto en el que se produce la adquisición de la lengua materna con la presentación de un vocabulario no sólo comprensible, sino incluso comprendido como indica Ellis (1994). Tras su proceso en el DAL (Dispositivo de Adquisición Lingüística), pasaría a ser considerado como conocimiento adquirido y perfectamente utilizable para la producción de mensajes. Con esto no estamos ni siquiera considerando la posibilidad de desterrar el aprendizaje, sino demarcar su terreno dentro de la adquisción de una segunda lengua. Dicho aprendizaje, a diferencia de la adquisción, conlleva unos procesos muy distintos ya que una vez procesado en el DAL, el conocimiento aprendido debe pasar por un proceso de monitorización antes de poder ser utilizado en la producción lingüística. Por tanto, el uso de la multi- 
media para la adquisición léxica debe combinarse con el aprendizaje, para obtener los mejores resultados. Dicho de otra manera, debemos considerar la adquisición, enseñanza y aprendizaje de una lengua distinta de la materna basada en dos procesos complementarios, uno implícito o adquisición y otro explícito o aprendizaje.

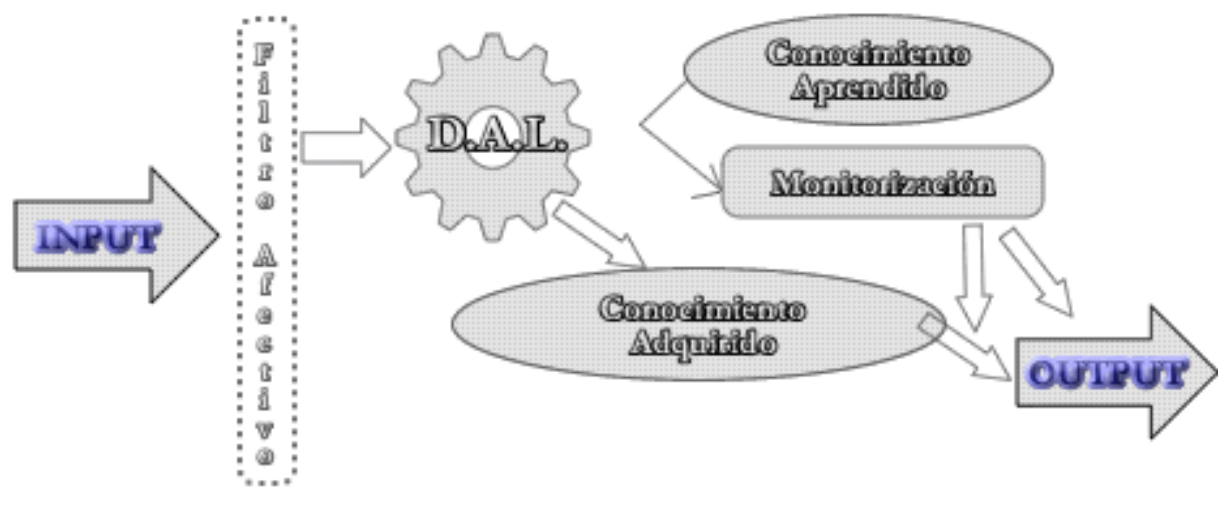

\section{Gráfico 1: Modelo sobre la adquisición y producción lingüística (Krashen, 1982, pp. 16 y 32) / (Gregg, 1984) [adaptado]}

Una vez introducida la idea sobre la importancia de que un input sea comprensible y los medios gráficos como herramientas para conseguirlo, debemos destacar que la adquisición y posterior utilización del vocabulario, como otros muchos elementos del lenguaje, no es un proceso simple sino bastante complicado y elaborado. Se trata de un proceso mental que va más allá de la simple decodificación de la información, y su posterior codificación por parte del individuo. Fue Paivio (1971) quien destacó que en el proceso de adquisición del vocabulario, la presencia de un estímulo visual y un estímulo verbal activa dos códigos distintos e independientes: los imagens incluidos dentro de un sistema de almacenamiento / proceso de imágenes y representaciones gráficas; y los logogens, almacenados como elementos discretos en el sistema verbal como palabras y oraciones. Estos dos sistemas, el verbal y el visual, no funcionan de forma aislada, sino en contínua interacción gracias a:

1. Conexiones de representación que actúan como vínculos entre ambos sistemas y el estímulo. De esta manera, el estímulo verbal activa a su vez los dos sistemas. A modo de ejemplo, siempre que veamos, escuchemos o leamos el término árbol, activaremos el sistema verbal y obtendremos una representación visual mental de dicho objeto. 
2. Conexiones referenciales como puentes entre ambos sistemas verbal y visual de manera que, un "imagen" determinado activará un logogen en el sistema verbal. Siguiendo con el ejemplo anterior, siempre que veamos, escuchemos o leamos árbol, se activará el logogen de árbol. Esta relación, sin embargo, no es uno a uno, sino que es uno a muchos. Como destaca Rieber (1994), árbol puede activar perenne, caduco, mediterráneo, de montaña, chopo, pino, etc.

3. Estructuras asociativas directamente relacionadas con la activación o proceso de la información contenida en cualquiera de los dos sistemas. Hay, sin embargo, diferencias destacables en cómo se llevan a cabo dicha operación y proceso: de tipo paralelo o de sincronización en el sistema visual, y secuencial en el verbal.

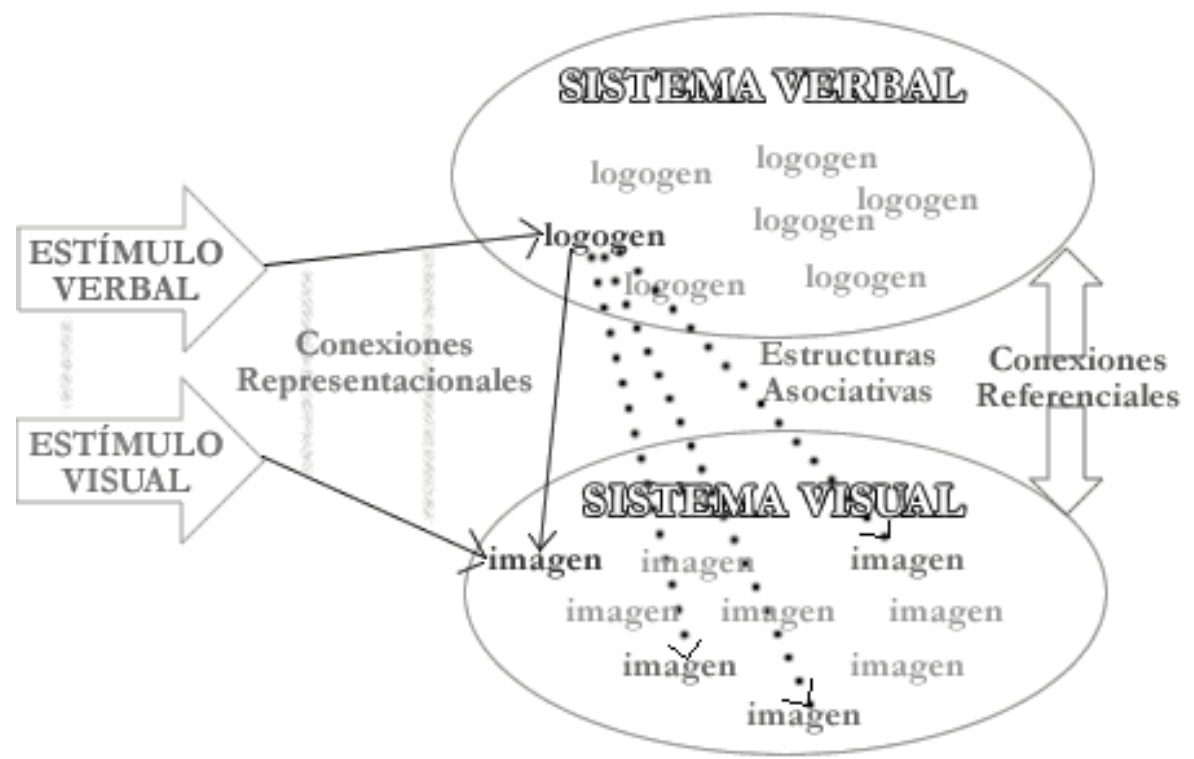

Gráfico 2: Sistemas verbal y visual frente al estímulo de Rieber y Kini

Volviendo a la actualización de la teoría y su aplicación práctica en ELAO, los sistemas actuales que combinan recursos gráficos, estáticos o en movimiento, con la información verbal, escrita u oral, están centrados en el individuo así como en el diseño de un entorno que facilite el proceso cognitivo de los mensajes. Esta codificación se presenta también por medio de lo que Doolittle, McNeill, Terry y Scheer (2005) denominan Teoría Cognitiva Multimedia y definen como supuesto de canal dual. Gracias a la multimedia, el individuo posee dos cana- 
les distintos para el proceso de la información, uno verbal y otro visual. De esta forma, si un alumno ve una imagen o un vídeo asociados a una explicación, oral o escrita, el canal visual se encargará del proceso de los primeros, mientras que es verbal se encargará de la narración. Esta forma dual de presentar la información, imitando el proceso natural de adquisición de la lengua materna, se ha transformado en una vía actual muy importante para favorecer la adquisición y retención léxica, a juzgar por los resultados obtenidos por numerosos investigadores en sus experiencias con alumnos reales. Por una parte, el uso de multimedia tiene una acción directa sobre la construcción de inferencias causales y, por otro, sobre la creación de un modelo de situación que facilita la adquisción de vocabulario desconocido. Experiencias como las de Lyman-Hager, Davis, Burnett y Chennault (1993), Brown (1993), Chambles y Chambles (1994), Gan, Low y Yaakub (1996), Raphan (1996), Master-Wicks, Postlewate y Lewental (1996), Chun y Plass (1996), Ihenacho (1997), Lomicka (1998), Al-Seghayer (2001), Sáez (2005), entre otros, respaldan la idea que un grupo experimental (GE) con material de tipo multimedia sobre un texto, frente a uno de control (GC) con material impreso, se presenta superior a la hora de la comprensión escrita, adquisición y retención léxica.

Hasta este momento nos hemos referido a los recursos gráficos en general, pero hay también que destacar diferencias notables en el uso de uno u otro y su combinación, tanto en relación con los fines perseguidos, como las posibilidades metodológicas que pueden ofrecer, ya sea como imagen fija o secuencia de éstas en movimiento. Como demuestran las experiencias realizadas por Ihenacho (1997) y Al-Seghayer (2001), tomadas como referente para nuestra adaptación al ámbito de estudiantes españoles de Enseñanza Secundaria Obligatoria (ESO) de nuestro estudio, un texto dado en combinación con recursos gráficos en movimiento, se presenta como mucho más efectivo que uno tradicional basado en imágenes estáticas. Aunque en un primer acercamiento esto parece ser cierto y como veremos más adelante, deberíamos hacer ciertas salvedades. Es indudable que la animación es mucho más poderosa que un dibujo o una fotografía, ya que la primera puede, entre otras muchas características, representar tanto conceptos concretos como abstractos, finalidad que no la puede realizar los segundos debido a sus limitaciones. Sin embargo, la animación puede desorientar al estudiante si presenta demasiada información haciéndole perder el control sobre la comprensión de un texto dado y sobre el recuerdo de las imágenes contenidas en un vídeo, como demostró Chun y Plass (1996) con su segunda experiencia de comparación de ambos formatos. 
Es aquí donde entra en contexto esta investigación, como intento de adaptar esta base teórico-experimental al contexto y alumnos españoles. Dicha experiencia se ha basado en la necesidad de analizar la efectividad de los medios gráficos estáticos y en movimiento con alumnos españoles de ESO, L1 castellano y lengua objetivo (Lo) inglés, para la comprensión escrita, adquisción léxica, su retención a corto (RCP) y a largo plazo (RLP). La razón principal es que son muy pocas las investigaciones realizadas con este tipo de alumnado y prácticamente inexistentes, las que combinan la comparación de material tradicional impreso y con recursos multimedia. Además, frente a una concepción universalizadora sobre la adquisición léxica, se necesita investigar la vertiente individualizadora de dicho proceso, de adaptación al material humano al que van dirigidas las actividades. No debemos olvidar que el marco educativo legal actual postula y destaca la necesidad de individualizar tanto en el aprendizaje, como en hacer de la enseñanza una base esencial para una educación de calidad. Es interesante, por tanto, aun partiendo de una base general, analizar las distintas variables que afectan a dicho proceso de adquisición de vocabulario básico en una lengua extranjera, para, de este modo, identificar las variantes individuales que presentan los diferentes alumnos, tanto en el formato impreso-tradicional, como en el experimental-multimedia.

De forma más específica, entre los presupuestos e hipótesis que nos marcamos desde el comienzo de la presente experiencia podemos destacar que, en primer lugar, ofrecer ayudas multimedia favorece la comprensión de un término desconocido por el individuo, la inferencia, la adquisición y la retención del mismo, además de motivar al alumno. En segundo lugar, la ayuda multimedia reduce en gran medida el número de palabras que, debido a su dificultad, el individuo aparta en detrimento de la comprensión del texto. Como sabemos y sufrimos como docentes, es una tendencia por desgracia bastante generalizada. En tercer lugar, contextualizar un término gracias a la imagen, animación, texto y sonido, tiene una repercusión tan importante sobre la adquisición y retención del vocabulario, que un formato lineal estático como el material impreso, jamás podría ofrecer. En cuarto lugar, el formato multimedia produce en el estudiante un sentimiento de autosuficiencia que, sin duda, refuerza su autoestima. Y, por último, la comprensión de un texto es más natural, rápida y efectiva con actividades multimedia y el uso de ELAO, que con las de tipo tradicional. 


\section{Método}

\section{Participantes}

Partiendo de la selección de un texto graduado con un nivel accesible para alumnos de $4^{\mathrm{o}}$ de ESO, se seleccionaron 28 alumnos de dicho curso (13 chicos y 15 chicas), todos ellos con un trasfondo socio-cultural e instrucción educativa similares. Se trata, por tanto, de un grupo bastante homogéneo y fiable en cuanto a la obtención de datos para nuestra investigación.

\section{Instrumentos y procedimiento}

Estos participantes fueron sometidos a un pre-test (T0), siguiendo el formato de los Vocabulary Level Tests de Nation (1990), que persiguiría un doble propósito: una evaluación de su nivel léxico y obtener aquellas palabras que desconocían, tanto por su significado como por su uso, para ser utilizadas como indicadores para la experiencia ya que no podrían ser confundidas como conocimiento previo. En cuanto a la primera faceta del test, los resultados obtenidos fueron 2 alumnos con un nivel alto (70\%-100\% de respuestas acertadas), 6 alumnos con nivel medio (50\%-69\%) y 20 con nivel bajo (0\%-49\%), dentro de un intervalo de conocimiento léxico de 1000-1200 palabras.

Gracias a los resultados de dicho pre-test, en su vertiente de descubrir el nivel real de vocabulario en inglés de cada uno de los participantes, se dividió este grupo de estudiantes en dos subgrupos de 14 individuos, GC y GE. De esta forma, ambos grupos estaban formados por individuos con niveles alto, medio y bajo en un mismo porcentaje (1 nivel alto, 3 medio y 10 bajo en cada uno). Con esto, aseguramos que la experiencia y posterior contraste de datos, se produjeran bajo un entorno científico coherente. Con el GC, realizamos las actividades de tipo tradicional impreso, mientras que con el GE utilizamos las actividades multimedia que fueron diseñadas para este experimento. El espacio en el que se desarrollará la experiencia también va a ser diferente. Mientras que el GC llevó cabo sus actividades en un aula tradicional, el trabajo del GE se realizó en un aula de informática. En el caso del primer grupo, los participantes tuvieron a su disposición tan sólo una copia del texto con sus respectivas imágenes, actividades de refuerzo (respuestas múltiples o multiple choice, verdadero o falso, unir 
palabra/gráfico con su definición, etc), un diccionario inglés-español / español- inglés, una gramática, papel y un bolígrafo.

Como ya mencionamos anteriormente, el GE realizaría unas actividades multimedia diseñadas para esta experiencia usando Adobe Flash. Estas actividades se desarrollaron como una adaptación de las tradicionales impresas del GC. Las palabras del texto se transformaron en vínculos que reproducían animaciones que resumían brevemente su significado, a excepción del término least (imagen estática) y catch (animación con excesos gráficos y de información), en lo que denominamos vocabulary machine (máquina de vocabulario). Además, como refuerzo y ofrecer la posibilidad de contrastar y ampliar conocimientos sobre el significado de los términos, su uso y restricciones gramaticales, la plataforma ofrecía la posibilidad de acceso en Internet a un diccionario en línea, el Meriam Webster (http://www.m-w.com), y una gramática y ejercicios, Grammar Bytes (http://www.chompchomp.com). Para facilitar la comprensión del texto y la contextualización de las palabras desconocidas, incluimos una sección en el programa que titulamos el cine. En un entorno que recordaba una sala cinematográfica, colocamos una pantalla en la que se representaba la historia del texto, gracias a una animación por frase que se presentaba a modo de subtítulo. Finalmente, incluimos tres juegos sencillos como actualización de los ejercicios de refuerzo del GC. Se trata de Shoot the Duck (Dispara al Pato) como ejercicio de respuestas múltiples, Good \& Evil (Bueno y Malo) como actividad de verdadero o falso, y Restore the System (Restaura el Sistema) para unir animaciones con su término.

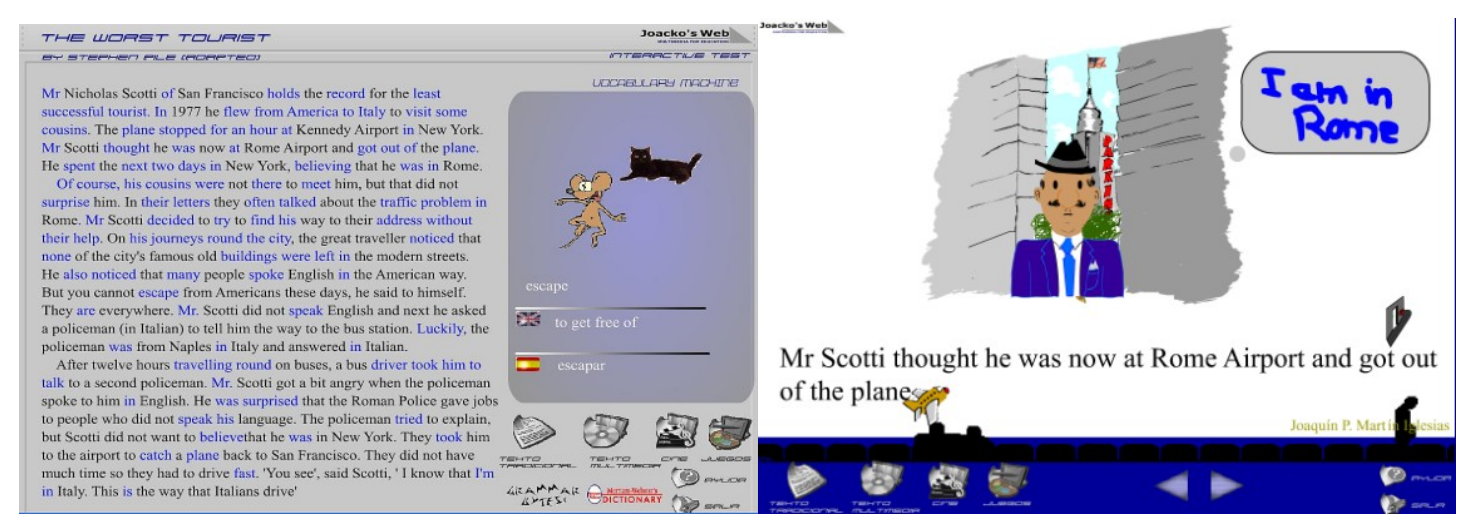

Gráfico 3: Capturas del texto interactivo y del cine de las actividades del GE 


\section{Resultados}

Para obtener los datos y resultados necesarios para la comparación de la efectividad de uno y otro formato, que aunque no de carácter universal, ya que es necesario un número mayor de participantes, sí resultaron significativos, tanto el GC como el GE realizaron sus respectivas actividades durante tres sesiones de 50 minutos aproximadamente. Una vez finalizadas, justo al término de la última, se realizó un test (T1), similar en formato al pre-test T0, para evaluar el vocabulario desconocido que habían adquirido. Los resultados obtenidos en ambos grupos fueron los siguientes:

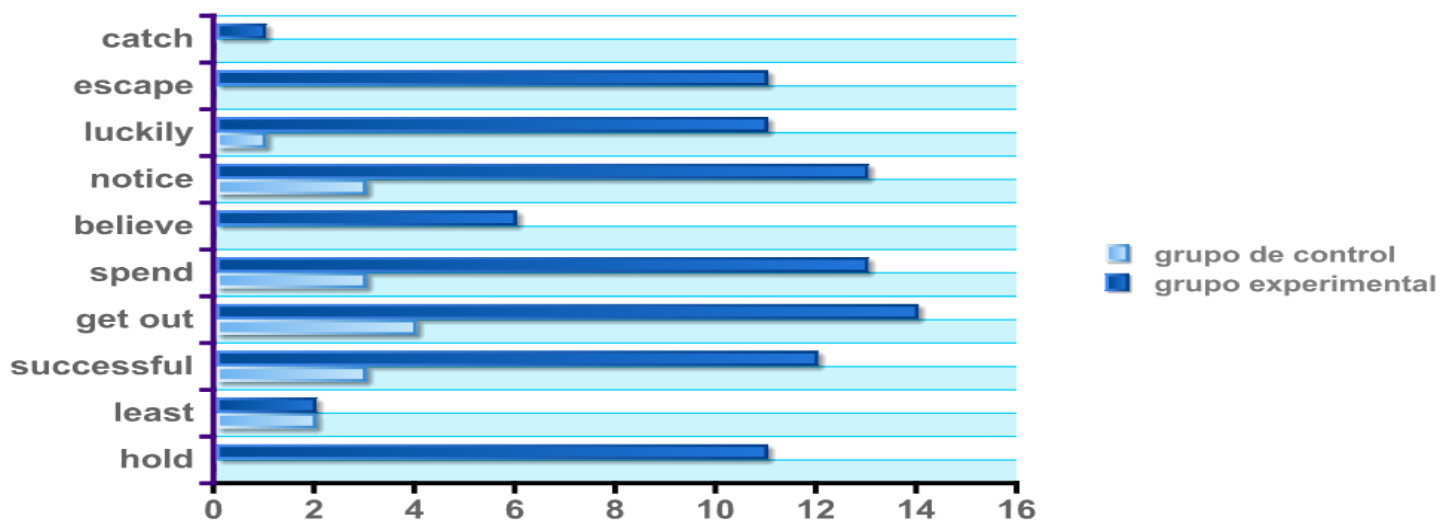

Gráfico 4: Número de adquisiciones del GC y el GE en el T1

Como podemos observar, el número de aciertos del GE, que utilizó las actividades de tipo multimedia, es mayor si lo comparamos con el GC que utilizó el medio impreso. Cada uno de los aciertos, como mencionábamos anteriormente, significa la adquisición de un término determinado del texto. Siendo el máximo de aciertos-adquisiciones de catorce, como número de participantes en cada grupo, nos llama la atención especialmente que la diferencia es aún más clara en "hold” (GC cero adquisiciones, frente a 11 del GE), "believe” (GC cero adquisiciones, frente a seis en el GE), "escape" (GC cero adquisiciones, frente a 11 en el GE), "get out" (GC cuatro adquisiciones, frente a catorce en el GE), entre otros términos.

La razón principal, como ya vaticinábamos de forma teórica, radica en dos aspectos del formato multimedia frente al medio escrito. Como mencionábamos en la instrucción teórica sobre la Teoría de la Codificación Dual, la utilización del formato gráfico y audio asociado a la información escrita favorece la adquisición léxica de forma natural. Esto hace que, como resultado, el individuo integre dicho vocabulario nuevo de forma más efectiva en su memoria. 
Además, el formato multimedia gracias a la motivación que produce en el estudiante, cómo llama la atención del individuo y facilita que la palabra sea recordada ya que, con visualizar mentalmente el gráfico, el estudiante puede acceder también a su significado. Por tanto, esto hace que la adquisición sea más numerosa y efectiva en el GE. Por otra parte, la animación permite la recreación del movimiento (hold-mantener, escape-escapar y get out-salir), así como la representación de conceptos abstractos (believe-creer) que son campos en los que la imagen estática está muy limitada.

Una semana de haber realizado el $\mathrm{T} 1$, los participantes se sometieron a un test para evaluar la RCP de similares características aunque con variaciones para evitar un efecto práctica, es decir, que los alumnos se acostumbraran a las preguntas y aprendieran de sus errores en el test anterior y no de las actividades realizadas. Los resultados obtenidos fueron los siguientes:

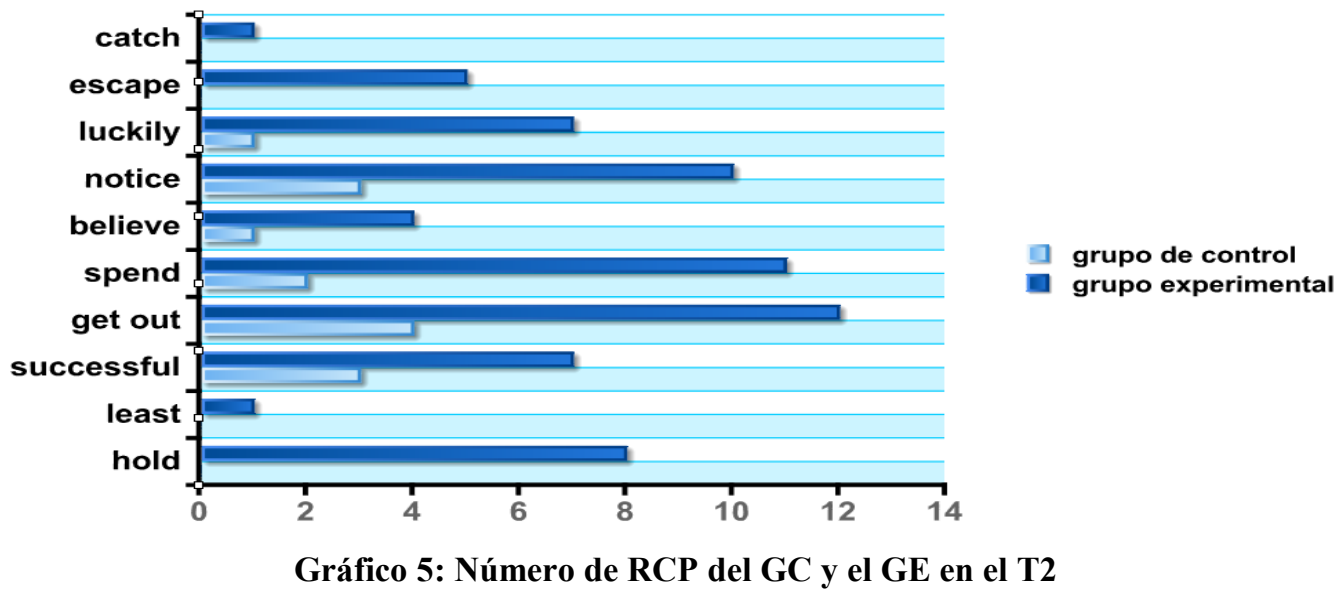

Como observamos por el gráfico, se mantiene la superioridad del GE frente al que utilizó el medio impreso que mencionábamos sobre la adquisición. Quince días después del T2, se realizó un último test (T3) con el fín de analizar cúantas de las palabras se retenían a largo plazo. De nuevo se realizaron modificaciones para evitar que los alumnos lo realizaran de forma mecánica. Los resultados fueron los siguientes:

Esto demuestra, de nuevo, que el vocabulario adquirido desde un texto con ayuda multimedia se retiene mejor en un periodo largo de tiempo, si lo comparamos con el que se produce utilizando un medio escrito exclusivamente. A la luz del gráfico anterior, parece que, aunque en un primer momento parezca que la retención a corto plazo queda estancada si com- 
paramos ambos grupos, definitivamente se demuestra la superioridad del GE a la de largo plazo en el T3. Esto se observa, aún más claro, si sumamos el número de adquisiciones en total de cada grupo en el T1, independientemente de la palabra, y lo comparamos con el T2 y el T3. De esta forma obtenemos:
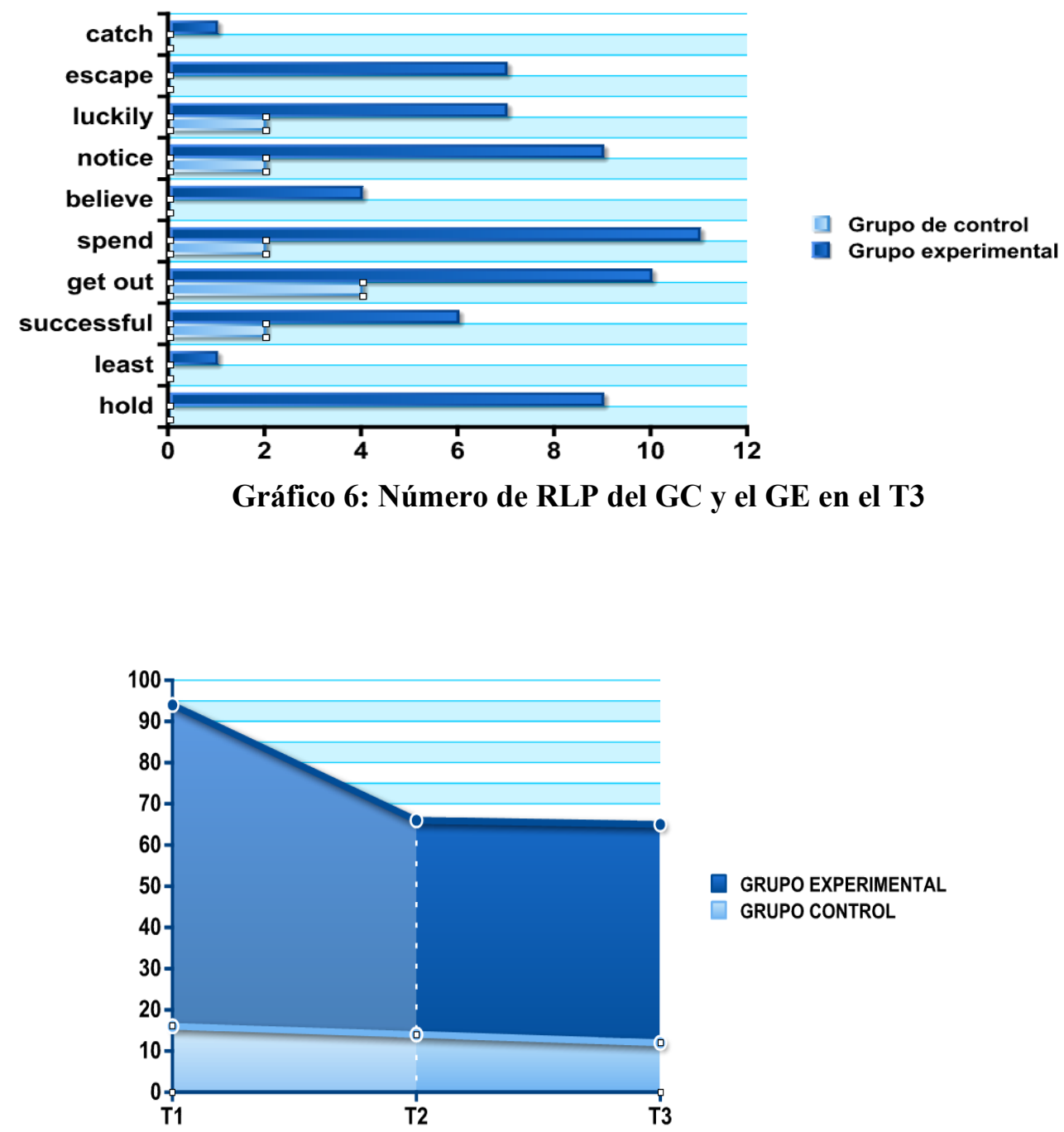

Gráfico 7: Suma total de adquisciones, RCP y RLP de ambos grupos

No nos podemos olvidar de los dos indicadores secundarios que incluimos en las acitividades del GE, least (imagen estática) y catch (animación con excesos gráficos y de información). Si comparamos los resultados del T1, T2 y T3, el número de adquisicionesretenciones es significativamente inferior al resto de palabras. Esto parece demostrar primero que aunque un término, least en este caso, se encuentre en un entorno multimedia sigue mantiendo sus características y limitaciones. Por otro lado, catch nos indica que las animaciones, como mencionamos anteriormente corroborado por la experiencia de Chun y Plass (1996), no deben excederse en la información aportada ni en su representación gráfica en movimiento, ya 
que puede producir la desorientación del individuo en el proceso adquisitivo y de compresión, así como dificultar la integración del vocabulario nuevo en el conocimiento previo.

\section{Discusión y Conclusiones}

A la luz de los resultados obtenidos, parece demostrarse en cierta manera que los estudios previos mencionados en nuestra introducción teórico experimental, sobre el efecto positivo de la animación en la adquisción léxica y su RCP/RLP, pueden ser trasladables al ámbito español con alumnos de ESO. Hemos dicho en cierta manera, puesto que no podemos olvidar las limitaciones que ya avanzábamos anteriomente, es necesario un número mayor de participantes para corroborarlo. De hecho, se está realizando en la actualidad una experiencia de dos cursos académicos (2006-2008) dentro de un proyecto de colaboración e investigación entre la UNED y el Departamento de Inglés del IES Alonso de Orozco de Oropesa (Toledo), subvencionado por la Junta de Comunidades de Castilla-La Mancha, del que el autor de este artículo es diseñador y coordinador, y al que se sumaran otros centros para mejorar este estudio previo gracias a la mejora de las actividades y un número mayor de alumnos participantes, entre $300 \mathrm{y}$ 500.

Volviendo al tema principal de este estudio, no nos podemos olvidar de dos temas principales que necesitan de un estudio mas preciso. Nos estamos refiriendo al efecto de los dos medios gráficos analizados sobre la comprensión escrita y la motivación de los alumnos. En cuanto al primero, tomando como referencia en esta ocasión los datos de aciertos, errores y las respuestas que los alumnos dejan sin contestar (ns/nc) obtenidos en el T1, T2 y T3 observamos lo siguiente:

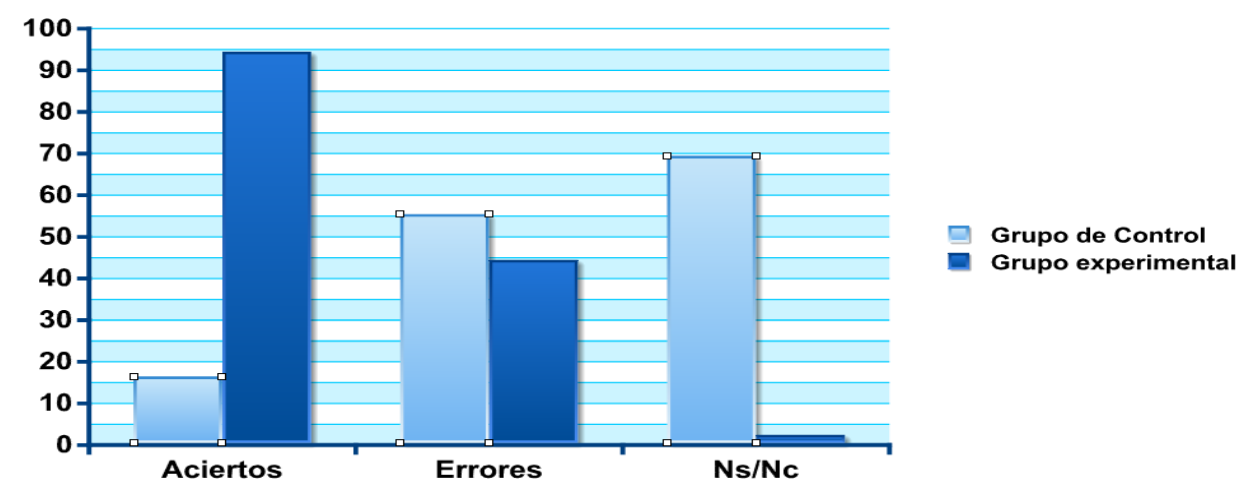

Gráfico 8: Totales de aciertos, errores y ns/nc de ambos grupos 
Parece claro que a mayor comprensión del vocabulario contenido en el texto, mayor será la comprensión del mismo. Si consideramos que esto es cierto, a la luz del gráfico anterior, también parece claro que el GE es muy superior al GC ya que, como podemos observar, los participantes se equivocan menos en la inferencia del significado. Además, si nos fijamos en la diferencia entre el GC y el GE en cuanto a no responder a las cuestiones de los tests, vemos que el mayor número se da en el primero. Esto nos lleva a pensar, y como veremos más adelante, que el uso de elementos multimedia no sólo favorece la adquisición, retención, y comprensión, sino que también motiva de tal forma que aporta al alumno un nivel muy alto de autoestima y seguridad, llevándolo a unos resultados excelentes en la comprensión de un texto. Esto es lo que observamos de forma muy importante en el grupo experimental, demostrando que el uso de distintos medios bajo un entorno ELAO se presenta como la mejor opción para facilitar la comprensión escrita a nuestros alumnos.

Para analizar dicha motivación, se realizó un intercambio de actividades durante una única sesión y una entrevista indidual posterior a los participantes. Aparte de ciertas cuestiones de evaluación interna de la experiencia, el 100\% de los alumnos de ambos grupos consideraron que las actividades multimedia fueron las más atractivas, divertidas y que preferirían realizar habitualmente en clase. Ante la pregunta ¿Cómo crees que hubieras aprendido más? 14 del GC y 12 del GE se decanta por las actividades multimedia, mientras que los otros dos restantes del GE no saben contestar.

Debemos considerar, por tanto, como muy positiva la experiencia realizada y que ha conseguido trasladar distintos puntos investigados en estudios previos, tanto teóricos como prácticos, al ámbito de la educación y los procesos de enseñanza/aprendizaje del inglés como lengua extranjera con alumons españoles de ESO. Sería muy interesante, sin embargo, que la investigación iniciada aquí, se desarrollara en el futuro teniendo en cuenta estos puntos, con el mismo objetivo de dar una visión distinta y complementaria a las existentes. El fin que hemos tratado de tener presente aquí ha sido hacer algo de luz en algo tan complicado y aun no explicado totalmente, como es la enseñanza de lenguas extranjeras en general, y la adquisición de vocabulario, RCP/RLP y la comprensión textual, en particular. 


\section{Referencias}

Al-Seghayer, K. (2001). The Effect of Multimedia Annotation Modes on L2 Vocabulary Acquisition: A comparative Study. Language Learning \& Technology, 5(1), 202-232.

Brown, C., (1993). Factors Affecting the Acquisition of Vocabulary: Frequency and Saliency of Words", en T. Huckin, M. Mayers, \& J. Coady (Eds.), Second Language Reading and Vocabulary Learning (pp. 263-286). Norwood: Alex.

Chambles, J.R., y Chambles, M.S., (1994) “The Impact of Instructional Technology on Reading/Writing Skills of $2^{\text {nd }}$. Grade Students”, Reading Improvement, 31 (3), 151-154.

Chomsky, N. (1986) Knowledge of Language: Its Nature, Origin and use, Praeger, Nueva York.

Chun, D. \& Plas, J. (1996). Effects of Multimedia Annotations on Vocabulary Acquisition. The Modern Language Journal, 80, 183-198.

Doolittle, P.E., McNeill A.L., Terry, K.P., y Scheer, S.B. (2005). Multimedia, Cognitive Load and Pedagogy. En VVAA, Multimedia in Education and Training, Hesdey: Idea Group.

Ellis, R. (1994). Factors in the Incidental Acquisition of Second Language Vocabulary from Oral Input: a review essay. Applied Language Learning, 5(1),1-32.

Gan, S.L., Low, F., y Yaakub, N.F., (1996). Modelling Teaching with Computer-Based Corcondancer in a TESL Preservice Teacher Education Program. Journal of Computing in Teacher Education, 12(4), 28-32.

Garret, N. (1989). Computers in Foreign Language Teaching and Research: A New Humanism. En W. H. Graves (Ed.), Computing Across the Curriculum: Academic Perspectives, pp. 101-139. TX, Academic Computing Pub., McKinney.

Gregg, K.W. (1984). Krashen's Monitor and Occam's Razor. Applied Linguistics, 5, 79-100.

Hofstetter, T. (1994). Is Multimedia the Next Literacy? Journal of Educational Communication \& Technology, 4 (2), 22-27.

Ihenacho, C. C. (1997). Effects of Two Multimedia Computer-Assisted Language Learning Programs on Vocabulary Acquisition of Intermediate Level ESL Students, T. Doct., Blacksburg.

Krashen, S., y Terrell, T.D. (1983) The Natural Approach. Oxford: Pergamon Press.

Krashen, S. (1985). The Input Hypothesis: Issues and Implications. Londres: Longman.

Levy, M. (1997). Computer-Assisted Language Learning: Context and Conceptualization, Oxford: O.U.P. 
Lomicka, L. (1998). To Gloss or not to Gloss: An Investigation of Reading Comprehensión Online. Language Learning \& Technology, 1(2), 41-50.

Lyman-Hager, M., Davis, N., Burnett, J., y Chennault, R. (1993). Us Vie de Boy: Interactive in French. En F.L. Borchardt \& E.M.T. Johnson (Eds.), Proceeding of CALICO 1993 Annual Symposium on Assessment, Duke University, Durham, pp. 93-97.

Martín, J. P. (2006). Aprendizaje de Vocabulario y ELAO: análisis experimental y comparativo entre actividades tradicionales y con recursos multimedia, en la enseñanza del inglés como lengua extranjera. Tesis Doctoral no publicada. Madrid: UNED.

Masters-Wicks, K., Postlewate, L., \& Lewntal, M., (1996). Developing Interactive Instructional Software for Language Acquisition. Foreign Language Annals, 29 (2), 217-222.

Nation, I.S.P. (1990). Teaching and Learning Vocabulary. Boston: Heile \& Heile Pub.

Paivio, A. (1971) Imaginery and Verbal Processes. Nueva York: Holt, Rinehart \& Winston.

Paivio, A. (1986) Mental Representation: A Dual-Coding Approach. Nueva York: OUP.

Pennington, M. (Ed.). (1996) The Power of CALL. Houston: Athelsan.

Raphan, D., (1996) “A Multimedia Approach to Academic Listening”, TESOL Journal, 6 (2), 24-28.

Rieber, L. y Kini, A. (1991). Theoretical Foundations of Instructional Applications of Computer Generated Animated Visuals. Journal of Computer-Based Instruction, 18(3), 83-88.

Rieber, 1. (1994). Computers, Graphics and Learning. Madison: Brown and Benchmark.

Sáez, A. (2005). Evaluación del apoyo de una imagen en la dificultad lectora en la lengua española. Electronic Journal of Research in Educational Psychology, 3(3), 51-88. www.investigacion-psicopedagogica.org/revista

Warschauer, M. y Healey, D. (1998). Computers and Language Learning: An Overview. Language Learning, 31, 57-71.

$\begin{array}{lll}\text { Abreviaturas: } & & \\ \text { CALL Computer Assited Language Learning } & \text { ICT } & \begin{array}{l}\text { Information and Communication } \\ \text { Technologies }\end{array} \\ \text { DAL Dispositivo de Adquisición Lingüística } & & \text { Lengua Materna } \\ \text { EFL English as a Foreign Language } & \text { L1 } & \text { Segunda Lengua } \\ \text { ELAO Enseñanza de Lenguas Asistida por } & \text { L2 } & \text { Sengua Objetivo } \\ \quad \text { Ordenador } & \text { Lo } & \text { Lengua } \\ \text { ELAOI Enseñanza de Lenguas Asistida por } & \text { RCP } & \text { Retención a Corto Plazo } \\ \quad \text { Ordenador Interactiva } & \text { RLP } & \text { Retención a Largo Plazo } \\ \text { ESO Enseñanza Secundaria Obligatoria } & \text { TIC } & \text { Tecnologías de la Información y Co- } \\ \text { GC Grupo de Control } & & \text { municación } \\ \text { GE Grupo Experimental } & & \end{array}$




\section{ELEMENTOS DE INTERÉS UNIVERSAL}

\section{Animación frente a imagen estática en la adquisción, RCP y RLP.}

Animación/vídeo

Imagen estática

- Uso coherente y controlado muy positivo

- Exceso de información, elementos no significativos y/o falta de coherencia animación-concepto, negativo (ruido informativo)

- Superiores a la hora de expresar conceptos abstractos y representar movimiento.

- Muy motivadores para el alumnado.

- Crea sentimiento de autosuficiencia que se traduce en el desarrollo de destrezas individuales para el auto-aprendizaje.

- La falta de coherencia en la información puede llevar a dificultades de adquisición

- Muy limitada a la hora de expresar conceptos abstractos y representar movimiento.

\section{RELACIÓN ENTRE LA ANIMACIÓN Y LAS IMÁGENES ESTÁTICAS}

Características de unos y otros

Demanda
- Teoría de la Codificación Dual de Paivio (1986).

- Sistema memorístico humana de Atkinson y Schiffrin (1968)

- El estímulo visual y verbal de Rieber y Kini (1991)

- Creación de imágenes mentales que son fácilmente transformables en conocimiento.

- Favorecen la adquisición, RCP y RLP del nuevo vocabulario.

- Hace comprensible la información presentada.

- Experiencia con un número mayor de participantes.

- Experiencia con alumnos de diferente entorno sociocultural, motivaciones, características, etc.

- Experiencia con un número mayor de parlabras-variablesindicadores.

- Experiencia en diferentes niveles educativos.

- Incluir otras variables como la integración de alumnos con necesidades educativas especiales (dificultades de visión, por ejemplo), rapidez en la consecución de las tareas y comprensión de un texto, desarrollo de destrezas extrapolables al auto-aprendizaje, etc. 